\title{
Perception of Junior Nurse Students and Nurse Interns Regarding Public Image of Nursing
}

\author{
Heba Nasser Rayan, Mona Mostafa Shazly, Nema Fathy Saad \\ Nursing Administration Department, Faculty of Nursing- Ain shams University, Egypt
}

\begin{abstract}
Background: The perception of nursing by the public plays an important role in determining the choice of nursing as a profession by young people. The aim of this study: to investigate the relationship between perception of junior nurse students and nurse interns regarding public image of nursing Subject and methods: the study was carried out at two different settings, namely faculty of nursing Ain Shams University and Ain Shams University Hospitals. The subjects of this study included two groups, 84 nursing students from first academic year and 94 from nurse interns. Using A descriptive, comparative design. Data were collected by using self -administered sheet which is based on Perceptions of Professional Nursing questionnaire. Results: The junior nurse students group has statistically higher mean score compared to Nurse interns regarding public image subscale and total perception scale. There was a highly statistically significant difference between junior nurse students \& nurse interns agreement upon the public image subscale $(\mathrm{P}<0.01)$. additionally that ; there was a statistically significant difference between junior nurse students \& nurse interns agreement upon all studied subscales , $(\mathrm{P}<$ 0.05).Conclusion: The junior nurse students group has statistically higher mean score compared to Nurse interns regarding public image subscale and total perception scale. there was a highly statistically significant intermediate strength positive correlation between value subscale and practice subscale perceived by junior nurse students. Recommendations the study findings, it was recommended that Conducting conference to appropriate orientation for junior undergraduates' nurse students\& nurse interns about the nursing profession, history of nursing, ensure the media portray positive image of nursing to recruit more staff to join nursing. Encour age future studies in order provide a complete picture of nursing image and factors influencing it.
\end{abstract}

Key words: nurse interns, nursing students, nursing image, perception

\section{Introduction}

The perception of nursing by the public plays an important role in influential the choice of nursing as a profession by young people. The perception of nursing by the public plays an important role in influential the choice of nursing as a profession by young people. Understanding the perception of nursing students about their career assist in identifying misconceptions and in sequence that could be helpful in planning public clarification about the profession (Oyedele et al., 2015). Perception is the way in which something is regarded, understood, or interpreted (The Oxford dictionary, 2013). Therefore nursing as a 'concept' is more than just a definition. It is part of a framework of communication, language of a group and this portrayed who nurses are and this definition 
carries a person's perception (Safari et al., 2011). perception about nursing is that it is regarded as a career more suitable for females than male and this was found out from a research made in the University of Ontario Canada (Bartfay et al., 2010).

The internship year is considered a time of transition from undergraduate nursing students to beginning level registered nurses. During this year nurse interns should acquire the values, attitudes, and goals fundamental to the nursing profession (El-Sayed; Zakaria; and; Shazely, 2007). A period of transition can be both challenging and exciting. Many factors need to be considered when examining the transition period, such as the stressful nature of the process, feelings of preparedness, trust in clinical skills and decision making, and the need for encouragement and socialization into the role. The transition from student to nurse can be stressful (Duchscher, 2009),

Nurses' image has always been affect among individuals in the profession. The choice to enter nursing profession, to remain in nursing, to upgrade nursing and to further a profession in nursing maybe as a effect of the nurses' perception of the image of the career (Emeghebo, 2012). Improving the public image of nurses is important, because the image impact nurses' recruitment and maintenance, drive to work, self image, selfconfidence and job satisfaction, client satisfaction, and policy making (National Students' Nurses Association, 2010).

Accordingly, the nursing image as a profession is affected by many factors, which decide the choice of nursing as a profession. These factors include: media, public image, social status, nurses themselves, having a family member, relative or a friend who is a nurse, role models, physician nurse relationships, nursing educators, nurse preceptors, expose to violence, exposure to health hazards and nursing education programs (Abdel El-Halem et al., 2011).
Nursing as a career has been characterized in the past with low social respect. Nursing in current years has made significant efforts to detach itself from the image of the past and it appears that succeeds. Taking into consideration first the criteria that helped in the progress of nursing science. It seems, nurses should work harder to communicate their professionalism to the public. Nurses can achieve that first, by speaking to civic and community groups about what nursing is and does (Price \& McGillis Hall, 2014), second by increasing their presence in the media as television \& radio debates and third by making better use of strategic positions, such as case manager, nurse educator or nurse specialist and use their professionalism to explain the public what their work really entails (Ten Hoeve; Jansen; Roodbol, 2014).

Promoting and sustaining positive nursing image is very essential in nursing profession to maintain nurses to be motivated to work and retain in the profession to be more professional and be a role model and mentor nurses everywhere you go to promote nursing image either in personal life or professional workplace. It is also very exciting to correct public media's misconception of nursing image by writing to them to keep notify and upgrade them regarding positive image in nursing to attract more staff to join nursing and retain in nursing and to enhance job satisfaction, job performance. By actively engaged in professional organization to speak to policy maker, write to media or newspaper to keep them well-informed of nurses' achievement and to get recognition from public (Zarea et al., 2009).

\section{Significance of the study}

Image of junior undergraduates' nurse students are important because they offer strategic clues towards successful recruitment of the next generation of nurses. While there have been many studies on the public image of nurses, there is a lack of research on 
how junior students' nurses actually perceive and interpret their public image based on their self-image and nursing practice, as well as how this interpretation affects their work behavior. A poor public image of nursing may affect not only nursing recruitment, but also nurses' attitudes towards work.

Accordingly, this study will investigate the perception of junior nurse students and nurse interns regarding public image of nursing.

\section{Aim of the study}

This study aims to investigate the relationship between Perception of Junior Nurse Students and Nurse Interns Regarding Public Image of Nursing through:

1. Assessing perception of junior nurse students regarding public image of nursing.

2. Assessing perception of nurse interns regarding public image of nursing.

3. Comparing between perception of public image of nursing between junior nurse students and nurse interns.

\section{Research Hypothesis}

There Is a difference in the Perception Public Image of Nursing between junior nurse students and nurse interns.

\section{Subjects And Methods}

\section{Research design}

A descriptive comparative design was utilized in conducting this study.

\section{Setting:}

The study was conducted at two different settings, namely; faculty of nursing
Ain Shams University and Ain Shams University Hospitals where the nurse interns are having their training.

University:

Faculty of Nursing Ain Shams

One department was included in this study. This was: Medical Surgical Nursing Department (part 1).this department was selected in which junior nursing students having their courses.

\section{Ain Shams University Hospitals:}

The study was conducted at Ain Shams University Hospitals where the nurse interns are having their training. and included the following hospitals: Ain Shams University Hospital, El-demerdash Hospital, Pediatric Hospital, and the academic institution of cardiac surgery.

\section{Study Subjects}

The subjects for this study included two groups namely; nursing students group and nurse interns group .

\section{Study Subjects}

The subjects for this study included two groups namely; nursing students group and nurse interns group .

*Nursing Students Group: included first academic year of nursing students of the faculty of nursing, Ain Shams University, their total number was( 184) student and sample size was (84) student after using the equation sample size affiliated to the Medical Surgical Nursing Department(part one).

$$
\text { Sample size }=\frac{\mathrm{Z} 1-\mathrm{a} / 22 \mathrm{p}(1-\mathrm{p})}{\mathrm{d} 2}
$$

$\mathbf{Z 1 - a} / \mathbf{2}=$ is standard normal varite at (5\% type 1 error $(\mathrm{p}<0.05)$ it is 1.96 and $1 \%$ type error $(\mathrm{p}<0.01)$ it is 2.58 As in majority 
of studies $\mathrm{p}$ values are considered significant below 0.05 is hence 1.96 is used in formula .

$\mathbf{P}=$ Expected proportion in population based on previous studies or pilot studies.

$\mathbf{d}=$ Absolute error or precision - has to be decided by researcher.

* Nurse Interns Group: the subject of this study consisted of all the available nurse interns were having their training at Ain Shams University Hospitals, and their total number was (94) nurse interns. includes:

*Ain Shams University Hospital: 30 nurse interns in five settings: Epidemic disease ICU, Emergency department, CCU, Neurologic ICU, Medical ICU

*El-Demerdash Hospital: 24 nurse interns in one setting: operations Unit.

*Pediatric Hospital: 20 nurse interns in three settings: Neonatal ICU, Emergency department, Intermediate ICU.

*the academic institution of cardiac surgery: 20 nurse interns in three settings; ICU Adult, CCU, Chest ICU.

\section{Tools of data collection:}

Two tool will be used to collect data to carry out this study:

The data for this study were collected by using a self -administered sheet which is based on Perceptions of Professional Nursing questionnaire.

\section{-Perceptions of Professional Nursing Tool (PPNT)}

\section{It includes three parts:}

Part one: this part was aimed at collection of Socio - demographic data of the study subject such as: age, gender, Marital status, presence of a nurse friend or relative, and family's reaction to students' enrollment...etc

Part two; This part was consisted of four statements to explore the subject's information about nursing, concerning: prior information about nursing, type of the source of information. Type of effect of this information on nursing image, reasons for enrollment to the faculty of nursing; feeling about nursing as a profession, and factors related to change in nursing image after joining faculty of nursing; and this tool developed by (Hallett, 2007; and Glacken, 2008) and this part excluded from nurse interns questionnaire.

Part three: This tool developed by Sand and Schaffer, (2006) and aimed to measure the perceptions of nursing image among nursing students and nurse interns. It consisted of 37 items, concerning three subscales, namely:

*practice; (13-items) which explore perceptions regarding the importance of teaching health promotion and disease prevention, autonomy, competence, accountability, and physician/nurse collaboration. (e.g Nurses with bachelor's degrees (BSNs) are better prepared to enter the nursing profession than nurses with associate degrees).

*values; (11-items) which explore perceptions regarding the importance of nursing, the characteristics of nurses, and their opinion of the profession as a whole. (e.g Nursing care is as important as physical therapy).

*public image; (13-items) which explore aspects of the profession that included whether the public considered nurses as professional, valuable, hard workers, intelligent, and other descriptors. (e.g Patients select a hospital based on nursing care). 
Results:

Table (1) demonstrates the demographic characteristics of studied junior nurse Students. As regard to age $(100 \%)$ of the junior nurse Students had age $(\leq \mathbf{2 0})$. Nearly two-thirds $(64.3 \%)$ of them were female. While in relation to marital status $(100 \%)$ of junior nurse Students were single. the majority of junior nurse Students $(59.5 \%)$ had a relative of friend in the nursing profession \& $(73.8 \%)$ of them had a positive family reaction about their enrolled to the nursing profession.

Table (2) demonstrates the demographic characteristics of studied nurse interns. As regard to age $(100 \%)$ of nurse interns had age $(<\mathbf{2 0})$. The highest percentage of them $(81.9 \%)$ of them were female. While in relation to marital status $(80.9 \%)$ of nurse interns were single and lowest percentage of them $(19.1 \%)$ were married. more than half of the study subject $(53.2 \%)$ had a relative of friend in the nursing profession \& $(71.3 \%)$ of them had a positive family reaction about their enrollment to the nursing profession.

Figure (1) shows that the majority of the Junior nurse Students were having prior information about nursing (78.6\%) compared to $(21.4 \%)$ of them had not prior information.

Figure (2) indicates that the main source of such information was relatives or friends (45.2\%) and only (1.2\%) of them got information from other sources such as healthcare settings usage.

Figure (3) shows that the highest percentage of the Junior nurse Students were positively influenced by prior information about nursing.

Table (3) shows the highest percentage of the Junior nurse Students were joined the
Faculty of Nursing due to the variety in career opportunity $(44.0 \%)$. While the lowest percentage was the challenging/ rewarding career $(2.4 \%)$ of the study subject $\&$ also table demonstrates the feelings of nursing students about nursing profession in front of others. The majority of them $(47.6 \%)$ proud $\& 26.1 \%$ of them were divert attention by changing the topic .However, $(8.3 \%)$ were shy.

Table (4) shows the factors related to change in nursing image after joining faculty of nursing in studied nurse Students, the highest percentage of these factors was public view about nursing ( $27.4 \%$ ) and $(23.8 \%)$ about working conditions while the lowest percentage was family member opinion $(1.2 \%)$.

Table (5) shows the junior nurse students group has statistically higher mean compared to Nurse interns regarding public image subscale and total perception scale.

Table (6) presents the correlations between the nursing image subscales items (Practice, Values, and Public Image) among junior nurse students. It show a highly statistically significant intermediate strength positive correlation between value subscale and practice subscale $(\mathrm{r}=.528)$. While there is non statistically significant, negatively correlation between public image subscale and other subscales (value \& practice subscales).

Table (7) shows that there a positive correlation between all nursing image subscales (value, practice, public image). It show a highly statistically significant between value subscale and practice subscale $(r=.583)$.and there is statistically significant between value subscale and public image subscales $(\mathrm{r}=.229)$ but there is no statistically significant between public image subscale \& practice subscale. 
Table (8) shows that there is highly statistically significant relation between junior nurse Students gender and practice subscale and their perception of public image total scale $(\mathrm{P}<0.02)$.

Table (1) Socio- demographic characteristics of Junior Nurse Students $(\mathrm{N}=84)$.

\begin{tabular}{|c|c|c|}
\hline Demographic data of junior nurse students & $\mathbf{N}$ & $\%$ \\
\hline \multirow{2}{*}{$\begin{array}{l}\text { Age } \\
\leq 20 \\
>20 \\
\text { Mean } \pm \mathrm{SD}\end{array}$} & $\begin{array}{c}84 \\
0\end{array}$ & $\begin{array}{l}100.0 \% \\
0.0 \%\end{array}$ \\
\hline & \multicolumn{2}{|c|}{$18.36 \pm 0.65$} \\
\hline $\begin{array}{l}\text { Gender } \\
\text { Male }\end{array}$ & 30 & $35.7 \%$ \\
\hline Female & 54 & $64.3 \%$ \\
\hline $\begin{array}{l}\text { Marital Status } \\
\text { Single }\end{array}$ & 84 & $100 \%$ \\
\hline Married & 0 & $0.0 \%$ \\
\hline $\begin{array}{l}\text { Presence of a nurse friend or relative } \\
\text { Yes } \\
\text { NO }\end{array}$ & $\begin{array}{l}50 \\
34 \\
\end{array}$ & $\begin{array}{l}59.5 \% \\
40.5 \%\end{array}$ \\
\hline $\begin{array}{l}\text { Family's reaction to Students' enrollment } \\
\text { Positive }\end{array}$ & 62 & $73.8 \%$ \\
\hline Negative & \multirow{2}{*}{$\begin{array}{c}17 \\
5\end{array}$} & $20.2 \%$ \\
\hline Neutral & & $6.0 \%$ \\
\hline
\end{tabular}

Table (2): Socio-demographic characteristics of Nurse Interns ( $N=94)$ :

\begin{tabular}{|c|c|c|}
\hline Demographic data of nurse interns & $\mathbf{N}$ & $\%$ \\
\hline $\begin{array}{l}\text { Age } \\
\leq 20\end{array}$ & $\begin{array}{c}0 \\
94\end{array}$ & $\begin{array}{c}0.0 \% \\
100.0 \%\end{array}$ \\
\hline $\begin{array}{l}>20 \\
\text { Mean } \pm \mathrm{SD}\end{array}$ & \multicolumn{2}{|c|}{$22.81 \pm 0.79$} \\
\hline $\begin{array}{l}\text { Gender } \\
\text { Male }\end{array}$ & 17 & $18.1 \%$ \\
\hline Female & 77 & $81.9 \%$ \\
\hline $\begin{array}{l}\text { Marital Status } \\
\text { Single }\end{array}$ & 76 & $80.9 \%$ \\
\hline Married & 18 & $19.1 \%$ \\
\hline $\begin{array}{l}\text { Presence of a nurse friend or relative } \\
\text { Yes }\end{array}$ & 50 & $53.2 \%$ \\
\hline NO & 44 & $46.8 \%$ \\
\hline $\begin{array}{l}\text { Family's reaction to Students' enrollment } \\
\text { Positive }\end{array}$ & \multirow{3}{*}{$\begin{array}{c}67 \\
20 \\
7\end{array}$} & $71.3 \%$ \\
\hline Negative & & $21.3 \%$ \\
\hline Neutral & & $7.4 \%$ \\
\hline
\end{tabular}


Figure (1): Distribution of the junior nurse Students according to their prior information about nursing $(\mathrm{N}=84)$.

\section{$78.6 \%$}

Yes No

Figure (2): Distribution of junior nurse Students according to their source of prior information about Nursing $(\mathrm{N}=84)$.

$$
13.1 \%{ }^{1.2 \%}
$$

$19.0 \%$

$45.2 \%$

family

other sources

Figure (3): Type of effect of junior nurse Students prior information on nursing image $(\mathrm{N}=84)$.

\begin{tabular}{lc}
\multicolumn{1}{c}{$19.0 \%$} & $45.2 \%$ \\
& \\
nurse friend /relatives & internet\& social media \\
family & other sources
\end{tabular}

Positive

$64.3 \%$

Negative 
Table (3) Agreement of junior nurse Students' upon the presence of information about nursing.

\begin{tabular}{|l|c|c|}
\hline junior nurse Students information about nursing & $\mathbf{N}$ & $\mathbf{\%}$ \\
\hline $\begin{array}{l}\text { *Reasons for enrollment to the faculty of nursing? } \\
\text {-Desire to help others }\end{array}$ & 28 & $33.3 \%$ \\
\hline -Challenges/rewarding career & 2 & $2.4 \%$ \\
\hline -Variety of career opportunity & 37 & $44.0 \%$ \\
\hline -Advice from relatives and friends & 10 & $11.9 \%$ \\
\hline - Others & 7 & $8.3 \%$ \\
\hline *Feelings of junior nurse Students about Nursing as a Profession & 40 \\
\hline -Proud & 7 & $47.6 \%$ \\
-Shy & 15 & $8.3 \%$ \\
\hline -Defensive & 0 & $17.9 \%$ \\
\hline -Attack of nursing Profession & 22 & $0.0 \%$ \\
\hline -Change topic (divert attention) & & $26.1 \%$ \\
\hline
\end{tabular}

Table (4): Factors Related to Change in Nursing Image after Joining Faculty of Nursing.

\begin{tabular}{|l|c|c|}
\hline \multirow{2}{*}{\multicolumn{1}{c|}{ Factors }} & \multicolumn{2}{c|}{ Junior Nurse Students } \\
\cline { 2 - 3 } & Frequency & Percent \\
\hline Relationship with medical staff & 14 & $16.7 \%$ \\
\hline Relationship with friends & 2 & $2.4 \%$ \\
\hline Family member opinion & 1 & $1.2 \%$ \\
\hline Public view about nursing & 23 & $27.4 \%$ \\
\hline Effect of faculty member & 13 & $15.5 \%$ \\
\hline Clinical training & 10 & $11.9 \%$ \\
\hline Working conditions & 20 & $23.8 \%$ \\
\hline
\end{tabular}

Table (5): Agreement of Junior Nurse Students and Nurse Interns as regard to The perception of Nursing Image Subscales.

\begin{tabular}{|c|c|c|c|c|c|c|c|}
\hline $\mathrm{Ng}$ Image Subscale & Group & $\mathrm{N}$ & Mean & SD & $\begin{array}{c}\text { Mean } \\
\text { Difference }\end{array}$ & $\mathrm{T}$ & $\mathrm{P}$ Value \\
\hline \multirow[t]{2}{*}{ Value Subscale } & $\begin{array}{r}\text { Junior Nurse } \\
\text { Students }\end{array}$ & 84 & 83.77 & 6.12 & \multirow{2}{*}{1.08} & \multirow[t]{2}{*}{1.12} & \multirow{2}{*}{0.263} \\
\hline & Nurse interns & 94 & 82.69 & 6.69 & & & \\
\hline \multirow[t]{2}{*}{ Practice Subscale } & $\begin{array}{r}\text { Junior Nurse } \\
\text { Students }\end{array}$ & 84 & 87.30 & 9.88 & \multirow{2}{*}{2.18} & \multirow{2}{*}{1.67} & \multirow{2}{*}{0.097} \\
\hline & Nurse interns & 94 & 85.12 & 7.45 & & & \\
\hline \multirow[t]{2}{*}{ Public Image Subscale } & $\begin{array}{r}\text { Junior Nurse } \\
\text { Students }\end{array}$ & 84 & 59.43 & 15.11 & \multirow{2}{*}{9.69} & \multirow{2}{*}{4.15} & \multirow{2}{*}{$0.000 *$} \\
\hline & Nurse interns & 94 & 49.73 & 15.95 & & & \\
\hline \multirow[t]{2}{*}{$\begin{array}{r}\text { Total Perception of } \\
\text { Public Image of nursing }\end{array}$} & $\begin{array}{r}\text { Junior Nurse } \\
\text { Students }\end{array}$ & 84 & 76.46 & 6.73 & \multirow[t]{2}{*}{4.49} & \multirow{2}{*}{4.10} & \multirow{2}{*}{$0.000 *$} \\
\hline & Nurse interns & 94 & 71.97 & 7.75 & & & \\
\hline
\end{tabular}


Perception of Junior Nurse Students and Nurse Interns Regarding Public Image of Nursing

Table (6): Correlation between the Nursing Image Subscales among Junior Nurse Students.

\begin{tabular}{|c|c|c|c|}
\hline \multicolumn{2}{|c|}{ Nursing Image Subscales } & Practice Subscale & Public Image Subscale \\
\hline \multirow[t]{3}{*}{ Value Subscale } & Spearman's Ranking correlation & $.528^{* *}$ & -.188 \\
\hline & coefficient & & .087 \\
\hline & P-Value & .000 & \\
\hline \multirow[t]{2}{*}{ Practice Subscale } & $\begin{array}{l}\text { Spearman's Ranking correlation } \\
\text { coefficient }\end{array}$ & & -.084 \\
\hline & P-Value & & .449 \\
\hline
\end{tabular}

Table (7): Correlation between the Nursing Image Subscales among Nurse Interns

\begin{tabular}{|c|c|c|c|}
\hline Nursing Image Subscales & & Practice Subscale & $\begin{array}{c}\text { Public Image } \\
\text { Subscale }\end{array}$ \\
\hline \multirow[t]{2}{*}{ Value Subscale } & $\begin{array}{l}\text { Spearman's Ranking } \\
\text { correlation coefficient }\end{array}$ & $.583^{* *}$ & $.229^{*}$ \\
\hline & P-Value & .000 & .027 \\
\hline \multirow[t]{2}{*}{ Practice Subscale } & $\begin{array}{l}\text { Spearman's Ranking } \\
\text { correlation coefficient }\end{array}$ & & .189 \\
\hline & P-Value & & .068 \\
\hline
\end{tabular}

Table (8) Relationship between junior nurse students' agreement on perception of Nursing Image Subscales and their gender

\begin{tabular}{|c|c|c|c|c|c|c|}
\hline $\mathrm{Ng}$ Image Subscales & Gender & $\mathrm{N}$ & Mean & SD & $\mathrm{T}$ & $\mathrm{P}$ value \\
\hline \multirow[t]{2}{*}{ Value Subscale } & Male & 54 & 84.58 & 6.44 & \multirow{2}{*}{1.64} & \multirow{2}{*}{0.104} \\
\hline & Female & 30 & 82.32 & 5.29 & & \\
\hline \multirow[t]{2}{*}{ Practice Subscale } & Male & 54 & 89.96 & 7.25 & \multirow{2}{*}{3.53} & \multirow{2}{*}{$0.001 * *$} \\
\hline & Female & 30 & 82.51 & 12.10 & & \\
\hline \multirow[t]{2}{*}{ Public Image Subscale } & Male & 54 & 60.40 & 14.72 & \multirow{2}{*}{0.79} & \multirow{2}{*}{0.434} \\
\hline & Female & 30 & 57.68 & 15.90 & & \\
\hline \multirow{2}{*}{$\begin{array}{l}\text { Perception of Public } \\
\text { Image Total Scale }\end{array}$} & Male & 54 & 77.98 & 5.85 & \multirow{2}{*}{2.90} & \multirow{2}{*}{$0.005^{* *}$} \\
\hline & Female & 30 & 73.72 & 7.42 & & \\
\hline
\end{tabular}


Table (9) Relationship between Nurse interns agreement on perception of Nursing Image Subscales and their gender.

\begin{tabular}{|c|c|c|c|c|c|c|}
\hline Ng Image Subscales & Gender & $\mathrm{N}$ & Mean & SD & $\mathrm{T}$ & $P$ value \\
\hline \multirow[t]{2}{*}{ Value Subscale } & Male & 77 & 81.77 & 6.53 & \multirow{2}{*}{-2.94} & \multirow{2}{*}{$0.004 * *$} \\
\hline & Female & 17 & 86.84 & 5.95 & & \\
\hline \multirow[t]{2}{*}{ Practice Subscale } & Male & 77 & 84.48 & 7.43 & \multirow{2}{*}{-1.81} & \multirow{2}{*}{0.073} \\
\hline & Female & 17 & 88.05 & 7.04 & & \\
\hline \multirow[t]{2}{*}{ Public Image Subscale } & Male & 77 & 50.25 & 16.21 & \multirow{2}{*}{0.66} & \multirow{2}{*}{0.511} \\
\hline & Female & 17 & 47.42 & 14.95 & & \\
\hline \multirow{2}{*}{$\begin{array}{l}\text { Perception of Public Image } \\
\text { Total Scale }\end{array}$} & Male & 77 & 71.65 & 8.14 & \multirow{2}{*}{-0.85} & \multirow{2}{*}{0.398} \\
\hline & Female & 17 & 73.42 & 5.64 & & \\
\hline
\end{tabular}

Discussion

The image of both nurses and nursing as a profession are very important in the successful recruitment and maintenance of staff in the healthcare industry (Meiring, 2010). Nurses' image has always been a concern among those in the profession. The decision to enter nursing profession, to remain in nursing, to promote nursing and to further a profession in nursing maybe as a result of the nurses' perception of the image of the profession (Emeghebo, 2012).

The study findings revealed that the majority of both the study subjects were females. According to (Alexander, 2010; Harding, 2012)The public generally perceives nursing as a feminine profession and this perception has deterred many qualified and interested males from taking up nursing as a profession, as any man entering into nursing is generally seen as acting against societal norms. The present study revealed that nearly two-thirds of junior nurse students were positively influenced by information given to them before entering the nursing profession by relatives/friends in nursing profession and then by media. As in
Egyptian culture, people tend to listen to others' previous experiences and advices. Any individual (male or female) who decides to enter into nursing already has certain preconceived ideas about the profession as well as certain expectations related to becoming a member of the nursing profession.

This is in the same line with (Abdel ElHalem et al., 2011), who found a significant correlation between presence of information and its effect on both students and the nursing image as a profession; and it seems that receiving information about nursing before joining the faculty- whether from family, friends or from schools of nursingplays an important role in influencing the students' image of nursing and their career choice. The findings revealed that the majority of the subjects had of their relative or friend in the nursing profession.A number of studies found that having family members as nurses were essential motives for undertaking nursing .Friends, parents and other family members had a positive impact on students' perceptions of nursing (Beck, 2012). 
This is in accordance with Abdel ElHalem et al., 2011), who conducted a study in Egypt about "Undergraduate Male Nursing students' Perception about the Image of the Nursing Profession". and indicated that there is significant relation between the image of nursing as a profession and the presence of family members, friends or relatives who were nurses. Price (2009) pointed out that the socialization experiences which the people had including their interactions with nurses greatly influence their view of nursing. The study finding of the present study revealed that The media is the second factor that influence, is still influencing, and most probably will continue to influence the public's image of nursing. It always pictures nursing as a low social status, subordinate, not respected, and female dominant profession, being presented as careless females who perform housekeeping activities and accept tips from others. This study result is congruence with (Mooney, Glacken \& O'Brien .,2008) The media play a major role in influencing the image and ideas the student has of nursing profession. This study result is dissimilar with (Rooper et al., 2006 ) who stated that media did not play any role in influencing the students in their career choice. None of the student mentioned it to be an influence though public and media play a major role in the influence of career choice. Then again there could be a possibility that media played a role indirectly just that the students did not look that as being important. The finding of the present study revealed that the highest percentage of junior nurse students were joined to faculty of nursing due to the variety of career opportunities, and this the first mentioned reason by study subject for entering nursing, this result in the same line with (Sand-Jecklin et al., 2006) students most frequently reported choosing nursing profession because of the a viability of career opportunities, jobs security, salary, and interest in nursing. Also this study finding is congruence with (Gutierrez et al.,2010) Another reason would be the expectations of employment. This boils down to job security, knowing that after studying it is easy to acquire a job and that as a healthcare professional, one cannot go without a job. this result is dissimilar with the results of (Gamel, 2006). Her study was carry out in Egypt to determine the image of nursing as a profession among undergraduate nursing students and interns. The results revealed that the availability of work and financial reward were the least mentioned causes among her subjects, as the subjects of such study were female nursing students. Moreover, the second mentioned reason by junior nurse students for entering nursing career in this research was helping people.

This result in the same line with Other studies reported that nursing students recognize nursing as a caring profession and as an opportunity to assist people gain a better health (Beck, 2012 ). The findings also displayed that the majority of junior nurse students were proud of nursing. and there is of nursing students divert attention by changing the topic in front of others, and. However, small percentages of them were shy \& no one of them attacked the profession. These results are congruence with those of (Milisen et al., 2010) study. Which revealed that $95.5 \%$ of nursing students were proud of becoming a nurse, and $83.4 \%$ of them would recommend family or friends to study nursing. The present study revealed that the highest percent of the study subjects were influenced by public view about nursing and the subjects' image was not improved after enrollment to the Faculty of Nursing, 
This study was congruence with (Shukri, 2005) also reported that nursing is still suffering from negative public image in the Arab world)., this study mentioned that the junior nurses' students in Nursing Faculty had the highest mean score regarding public valuing of nursing career image more than nurse interns. This study mentioned that there is a highly significant differences between gender and practice subscale and their perception of public image total scale in junior nurse students while in nurse interns there is a highly significant difference was found between gender and value subscale...

\section{Conclusion}

This study was undertaken to investigate the relationship between perception of junior nurse students and nurse interns regarding public image of nursing. the study findings concluded that The junior nurse students group has statistically higher mean score compared to Nurse interns regarding public image subscale and total perception scale. in means is statistically no significant difference between subject groups regarding other two subscales (value \& practice subscale).

The study results concluded that :

There was a highly statistically significant intermediate strength positive correlation between value subscale and practice subscale. while there is non statistically significant, negatively correlation between public image subscale and other subscales ( value \& practice subscales) perceived by junior nurse students .there was a highly statistically significant between value subscale and practice subscale. and there is statistically significant between value subscale and public image subscales but there is no statistically significant between public image subscale \&practice subscale perceived by nurse interns.

There was a highly statistically significant difference between junior nurse students \& nurse interns agreement upon the public image subscale, value subscale, $(\mathrm{P}$ $<0.01)$.in addition to that ; there was a statistically significant. difference between junior nurse students \& nurse interns agreement upon all studied subscale, $(\mathrm{P}<$ 0.05).this confirmed the research hypothesis which stated that There Is a difference in about perception Public Image of Nursing between junior nurse students and nurse interns.

\section{Recommendation:}

Based on findings of the present study, the following Recommendation are suggested:

1. Conducting conference to appropriate orientation for junior undergraduates' nurse students\& nurse interns about the nursing profession, history of nursing, nursing education programs and different clinical experiences.

2. Attract more individuals to the profession, and more focus on male students .

3. Perform Regular visits to Nursing schools and faculties for provision talks to strengthen the good image by acting as rolemodels and seek to dispel the misconceptions through seminars, brochures and advertisements for representing the realistic image of nursing.

4. Ensure that the nursing schools and faculties, media and professional journals 
should emphasize nursing roles and portray positive image of nursing career to recruit more staff to join nursing

5. Encourage future studies in order to devise strategies to reduce the issue of nursing shortage and turnover.

6. Encourage future studies with larger samples should be conducted in order to provide a complete picture of public image of nursing and factors influencing it.

7. Improved the image of the nursing profession through planning of the nursing curricula in order to be a magnet for attracting prevalent number of students to enter this profession and maintain professionalism in nursing practice.

8. Promoting and sustaining positive nursing image to keep nurses to be motivated to work and retain in the profession to be more professional and be a role model.

\section{References:}

Abdel El-Halem GE, El Hawashy ZI, Gamal

El-Dein AA, Taha EE, (2011)

Undergraduate Male Nursing students' Perception about the Image of the Nursing Profession. Journal of American Science; 7(3):614-23

Alan Miller, Edward, Denise A. Tyler, Julia Rozanova, and Vincent Mor (2012). "National Newspaper Portrayal of U.S. Nursing Homes: Periodic Treatment of Topic and Tone." The Milbank Quarterly. 4th ed. Vol. 90. New York: Milbank Memorial Fund,. 726. Print.
Annelie Meiring, (2010). The image of nurses as perceived by the south African public, A dissertation submitted in fulfillment of the requirements for the degree of Master in the Department of Nursing Science, Faculty of Health Sciences, University of Pretoria.

Bartfay W.J Bartfay, E, and Clow K. (2010). Attitudes and perceptions towards men in nursing education. Internet Journal of allied Health Sciences and Practice. 8(2) 20-24.

Beck C .(2012) The experience of choosing nursing as a career. Journal of Nursing Education. 2000; 39: 320-322. PMid:11052656 Published by Sciedu Press www.sciedu.ca/jnep Journal of Nursing Education and Practice, August 2012, Vol. 2, No. 3

Duchscher JEB (2009) Transition shock: the initial stage of role adaptation for newly graduated registered nurses. $J$ Adv Nurs 65(5): 1103-13

El-Sayed S.H., Zakaria A.M. and Shazely M.M. (2007) Management Function and Managerial Skills for Nurse Interns at Mansoura University Hospitals. The New Egyptian Journal of Medicine.; 36(5):1422.

Emeghebo L (2012). The Image of Nursing as Perceived by Nurses: U.S National Library of Medicine; National Institutes of Health, 32 (6):49-53

Gamel R. (2006)The image of nursing as a profession among undergraduate nursing students and interns. Unpublished Master 
Thesis, Faculty of Nursing: Alexandria University.

Gutierrez, San. R. S., Maranon, A. A., Poch, B. E., Prat, V. O. (2010). Factors influencing the choice of nursing studies [Spanish]. Enfermeria Clinica. July- Aug (40), 36-42.

Milisen K., De Busser T., Kayaert A., Abraham I. \& de Casterle B.D. (2010) The evolving professional nursing selfimage of students in baccalaureate programs: a cross-sectional survey. International Journal of Nursing Studies 47, 688-698.

Mooney, M., Glacken, M., O' Brien, F. (2008). Choosing Nursing as a career: A qualitative study. Nurse Education Today (2008) 28, 385- 392.

National Students' Nurses Association (2010). The Ripple Effect of Nursing: How Our Actions Reflects Our Image. Available at: http://www.nsna.org/Portals/0/Skins/NSN A/pdf/pubs_image_guidelines.pdf.accesse d 20 August 2012.

Oxford dictionaries. (2013). Perception. Oxford university press. Accessed on 7 February 2013. http://oxforddictionaries.com/ definition/english/perception

Oyedele Emmanuel A., Emmanuel Andy, Gaji Luka D., Goshit Jidauna D., Louis Okonkwo I. (2015) Perception of Undergraduate Nursing Students About Nursing Profession: A Study of University of Jos, Nigeria. International
Journal of Nursing and Health Science. Vol. 2, No. 5, , pp. 60-63.

Price, S.L., \& McGillis Hall, L. (2014). The history of nurse imagery and the implications for recruitment: A discussion paper. The Journal of Advanced Nursing, 70(7), 1502-1509. doi:10.1111/jan.12289

Safadi, R., Saleh, M., Nassar, O., Amre, H and Froeliche E. (2011). Nursing students' perceptions of nursing: a descriptive study of four cohorts. International Nursing Review, 58(4):420-427.

Sand-Jecklin, K. E., \& Schaffer, A. J. (2006) Nursing Students' Perceptions of their Chosen Profession. Nursing Education Perspectives, ; 27, 130-35

Shukri R.(2005) Status of nursing in the Arab world. Ethnicity \& Disease 2005;15(1Suppl 1): 88-89

Ten Hoeve, Y., Jansen G., \& Roodbol, P. (2014). The nursing profession: Public image, self-concept and professional identity. A discussion paper. The Journal of Advanced Nursing, 70 (2), 295-309. doi:10.1111/jan.12177

Zarea, K., Negarandeh, R., Dehghan-Nayeri, N., \& Rezaei-Adaryani, M. (2009). Nursing staff shortages and job satisfaction in Iran: Issues and challenges. Nursing and Health Sciences, 11(3), 326331. 